\title{
Design of E-Shape Microstrip Patch Antenna for UltraWideband Applications
}

\author{
B.Akhilesh babu ${ }^{1}$,G.Karthikeya ${ }^{2}$, G.Sharmila ${ }^{3}$, G.Rajkumar $^{4}$, M.Sujatha $^{5}$ \\ 1,2,3,4,5 Lendi Institute of Engineering and Technology,jonnada,vizianagaram
}

\begin{abstract}
This paper presents E-shape microstrip patch antenna with wideband wireless application. This shape will provide the broad bandwidth which is required in various application like remote sensing, biomedical application, mobile radio, satellite communication etc. The antenna design Probe feed technique is used in the experiment. Parametric study was included to determine affect of design towards the antenna performance. The performance of the designed antenna was analyzed in term of gain, return loss and radiation pattern. The design was optimized to meet the best possible result. The substrates FR4 and Duriod used in this have a dielectric constant of 4.4 and 2.2 respectively. The results show the wideband antenna is able to operate.

Index Terms: E-shape microstrip patch antenna, wideband.
\end{abstract}

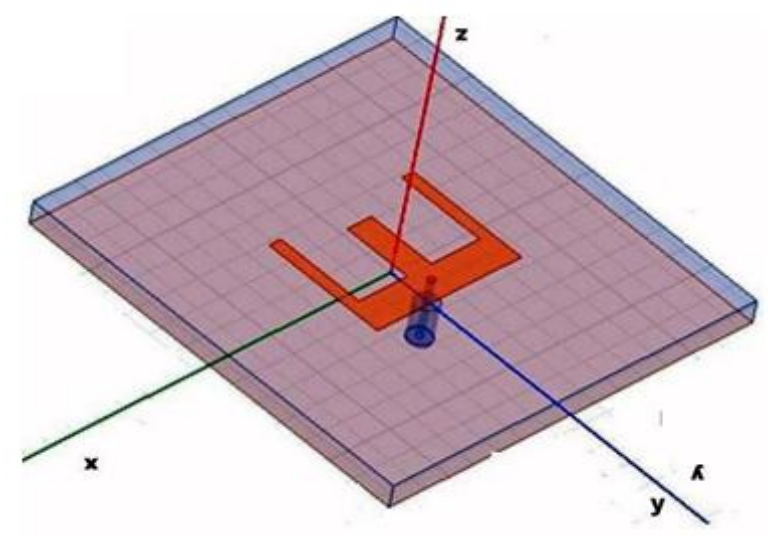

Figure 1: Design of E shaped patch antenna

\section{Introduction}

Microstrip patch antenna is a key building in wireless communication and Global Positioning system since it was first demonstrate in 1886 by Heinrich Hertz and its practical application by Guglielmo Marconi in 1901. Future trend in communication design is towards compact devices. Microstrip patch antenna have been well known for its advantages such as light weight, low fabrication cost, mechanically robust when mounted on rigid surfaces and capability of dual and triple frequency operations all these features, attract many researchers to investigate the performance of patch antenna in various ways. However, narrow bandwidth came as the major disadvantage for this type of antenna. Several techniques have been applied to overcome this problem such as increasing the substratethickness, introducing parasitic elements i.e. co-planar or stack configuration, or modifying the patch's shape itself. Modifying patch's shape includes designing an E-shaped patch antennas E-shaped patch antenna can increases bandwidth above 30\% compared to a regular rectangular patch antenna. Comparing both designs, the E-shaped is much simpler to construct by only adjusting length, width and position of slots. In this paper, a wideband single patch antenna is proposed as in Figure 1. The main objective of this paper is to optimize the base design in to obtain higher bandwidth.

\section{Design Methodology Of Radiating Element:}

Recently there have been numerous methods of enhancing the bandwidth of an antenna for example modifying the probe feed, using multiple resonances, using folded patch feed, or using the slotted radiating element.

As we know that as thickness increases the bandwidth increases accordingly. The slots making it to look alike inverted E shape; it demonstrated a bandwidth enhancement by $30 \%$.In this design an air-filled or 
foam has been essential to realize broadband characteristics.

\section{A. Setup for simulation}

The antenna's resonant properties were predicted and optimized using High Structure simulation software Ansoft version 11. The design procedure begins with determining the length, width and the type of dielectric substance for the give operating frequency as shown in flow diagram Fig.2. Then using the measurements obtained above simulation has been setup for the basic rectangular microstrip antenna and the parameters are optimized for the best impedance matching. Parallel slots which resembles the shape of $\mathrm{E}$ is designed and united; this increases the gain of the antenna. .Then dielectric substrate od dielectric constant of 1.0006 introduces to decrease the size of the antenna and to further enhance the bandwidth. At last the probe feeding is introduced for attaining a required bandwidth, resonating frequency and gain value. The proposed design methodology of the antenna is given in Fig.(2).

The main E shaped patch has Wa $\mathrm{x}$ La dimension. The antenna is fed by a SMA connector positioned at the center arm. The center of probe is positioned at ( $\mathrm{Wc} / 2, \mathrm{Lf})$. The width and length of the microstrip antenna are determine as follows

Where vo is the free-space velocity of light.

$$
\begin{aligned}
& W=\frac{1}{2 f_{r} \sqrt{\mu_{0} \varepsilon_{0}}} \sqrt{\frac{2}{\varepsilon_{r}+1}}=\frac{v_{0}}{2 f_{r}} \sqrt{\frac{2}{\varepsilon_{r}+1}} \\
& \varepsilon_{r e f f}=\frac{\varepsilon_{r}+1}{2}+\frac{\varepsilon_{r}-1}{2}\left[1+12 \frac{h}{W}\right]^{-1 / 2}
\end{aligned}
$$

Where the dimensions of the patch along its length have been extended on each end by a distance $\Delta L$, which is a function of the effective dielectric constant greff and the width to height ratio $(W / h)$, and the normalized extension of the length, is

The actual length of the patch (L) can be determine as

$$
\Delta L=0.412 h \frac{\left(\varepsilon_{r f f}+0.3\right)\left(\frac{W}{h}+0.264\right)}{\left(\varepsilon_{n f f}-0.258\right)\left(\frac{W}{h}+0.8\right)}
$$

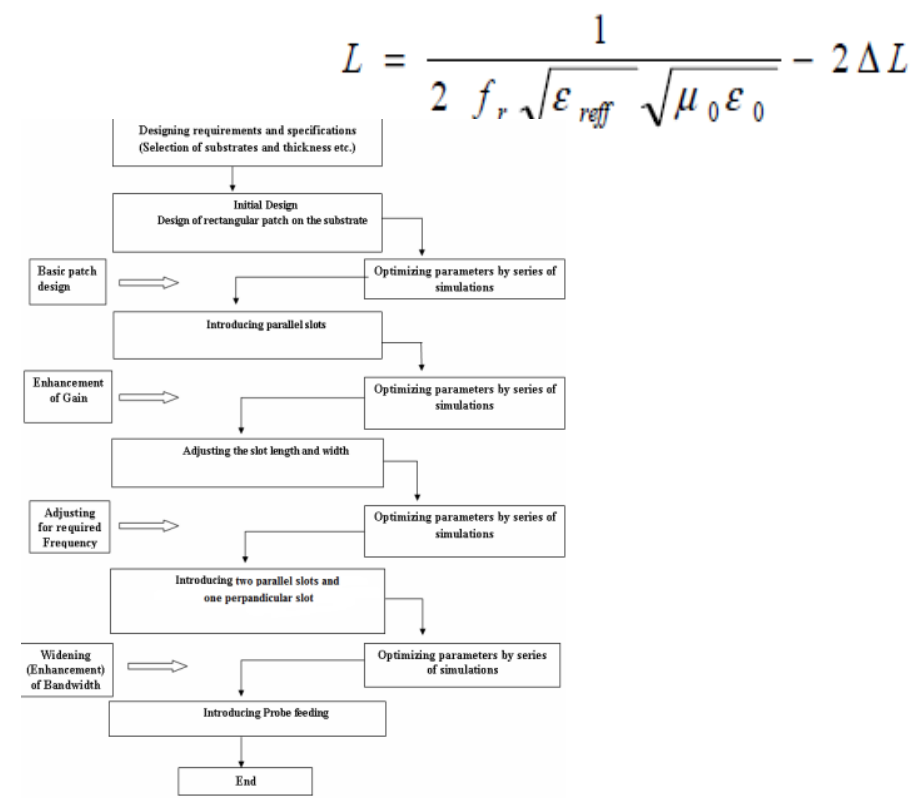

Fig.2 Flow diagram of designing procedure 


\section{B. Geometry of the antenna}

The geometry of the designed antenna is shown in the Fig.3.The antenna is made of a single patch on top, one layers of dielectric (air) and a vertical probe connected from ground to the upper patch.

Fig.3 Design geometry of E shaped patch antenna

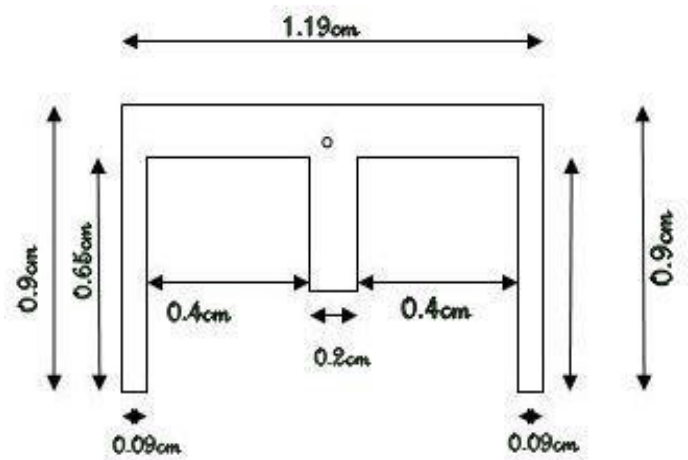

Parallel slots in this design are responsible for the excitation of next resonant mode i.e. main parallel slot excite resonant frequency. Slots length (LsA and LsB), slot width (S), main slot width (WsB) and center arm $(\mathrm{Wc})$ controls the frequency of the next resonant mode. Figure 4 shows the cut plane view of the antenna. The patch and ground are separated by closed-cell low loss air and it benefits to obtain wider bandwidth and higher gain.

Air gap was used as substrate and infinite ground was assumed. This paper design a finite set of ground dimension which is defined by $\mathrm{Wg} \times \mathrm{Lg}$. The designed values of this antenna design is shown in Table.

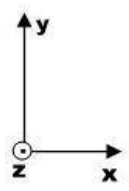

\begin{tabular}{|l|l|l|l|l|}
\hline Name & Value & Unit & $\begin{array}{l}\text { Evahuated } \\
\text { Value }\end{array}$ & Type \\
\hline Patch Dimensions & & & & \\
\hline PatchX & 1.19 & $\mathrm{Cm}$ & $1.19 \mathrm{~cm}$ & Design \\
\hline PatchY & 0.9 & $\mathrm{Cm}$ & $0.9 \mathrm{~cm}$ & Design \\
\hline -Substrate... & & & & Design \\
\hline subH & 62 & $\mathrm{mil}$ & $62 \mathrm{mil}$ & Design \\
\hline subX & 3 & $\mathrm{Cm}$ & $3 \mathrm{~cm}$ & Design \\
\hline subY & 3 & $\mathrm{Cm}$ & $3 \mathrm{~cm}$ & Design \\
\hline -Feed & & & & Design \\
\hline feedX & 0 & $\mathrm{Cm}$ & $0 \mathrm{~cm}$ & Design \\
\hline feedY & 0.3 & $\mathrm{Cm}$ & $0.3 \mathrm{~cm}$ & Design \\
\hline coax_inner & 0.025 & $\mathrm{Cm}$ & $0.025 \mathrm{~cm}$ & Design \\
\hline coax_outer. & 0.085 & $\mathrm{Cm}$ & $0.085 \mathrm{~cm}$ & Design \\
\hline feed_length & 0.25 & $\mathrm{Cm}$ & $0.25 \mathrm{~cm}$ & Design \\
\hline -Air Box & & & & Design \\
\hline Airbox_distance & 0.9993 & $\mathrm{Cm}$ & $0.9993 \mathrm{~cm}$ & Design \\
\hline -VirtualObjects & & & & Design \\
\hline VirtualObjects & 0.2998 & $\mathrm{~cm}$ & $0.2998 \mathrm{~cm}$ & Design \\
\hline
\end{tabular}

\section{Results And Discussions:}

The aim of this paper is to obtain better gain and bandwidth.

\section{A.For FR4 substrate}


Return loss

\section{B.For DURIOD substrate:}
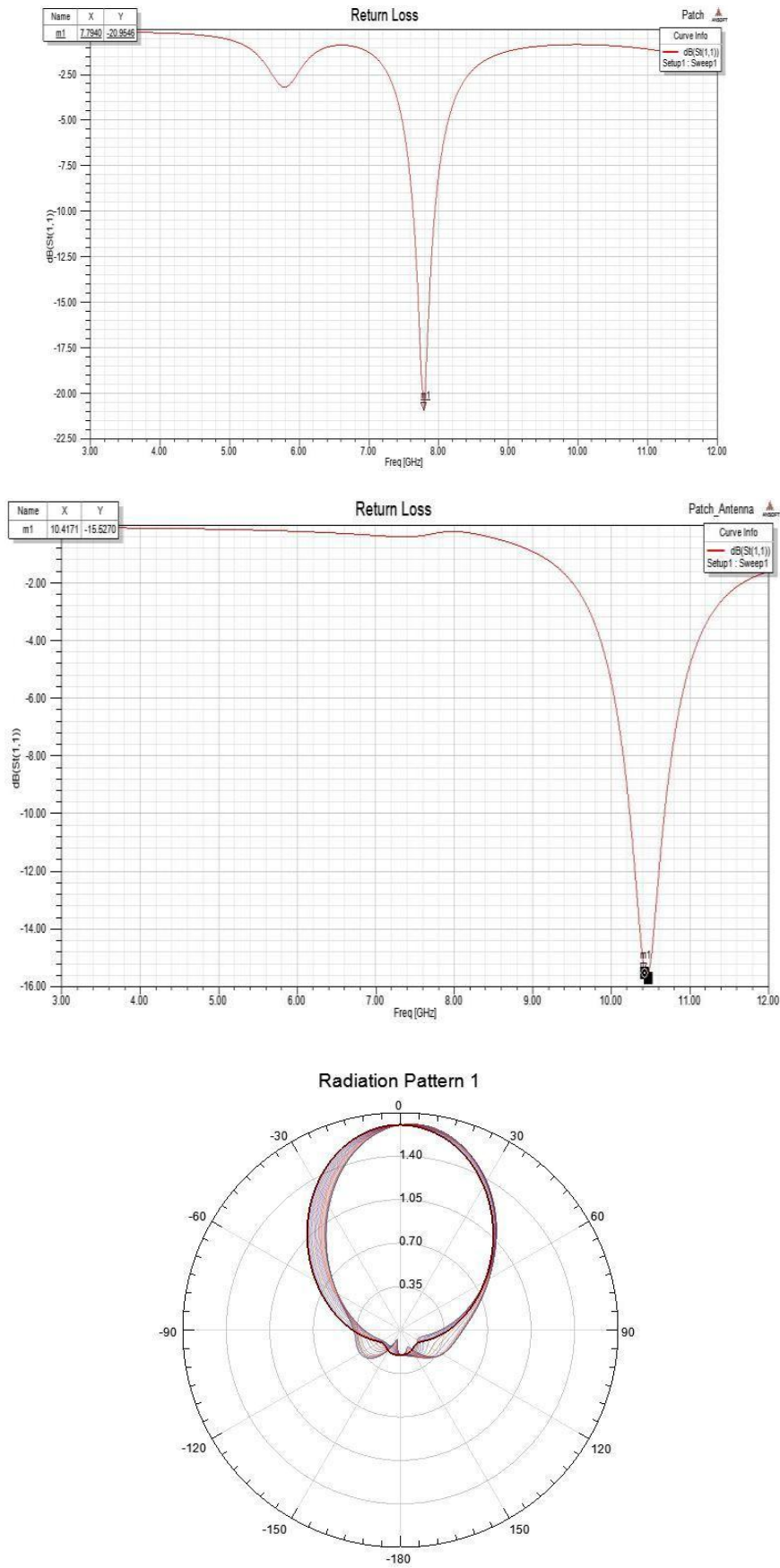

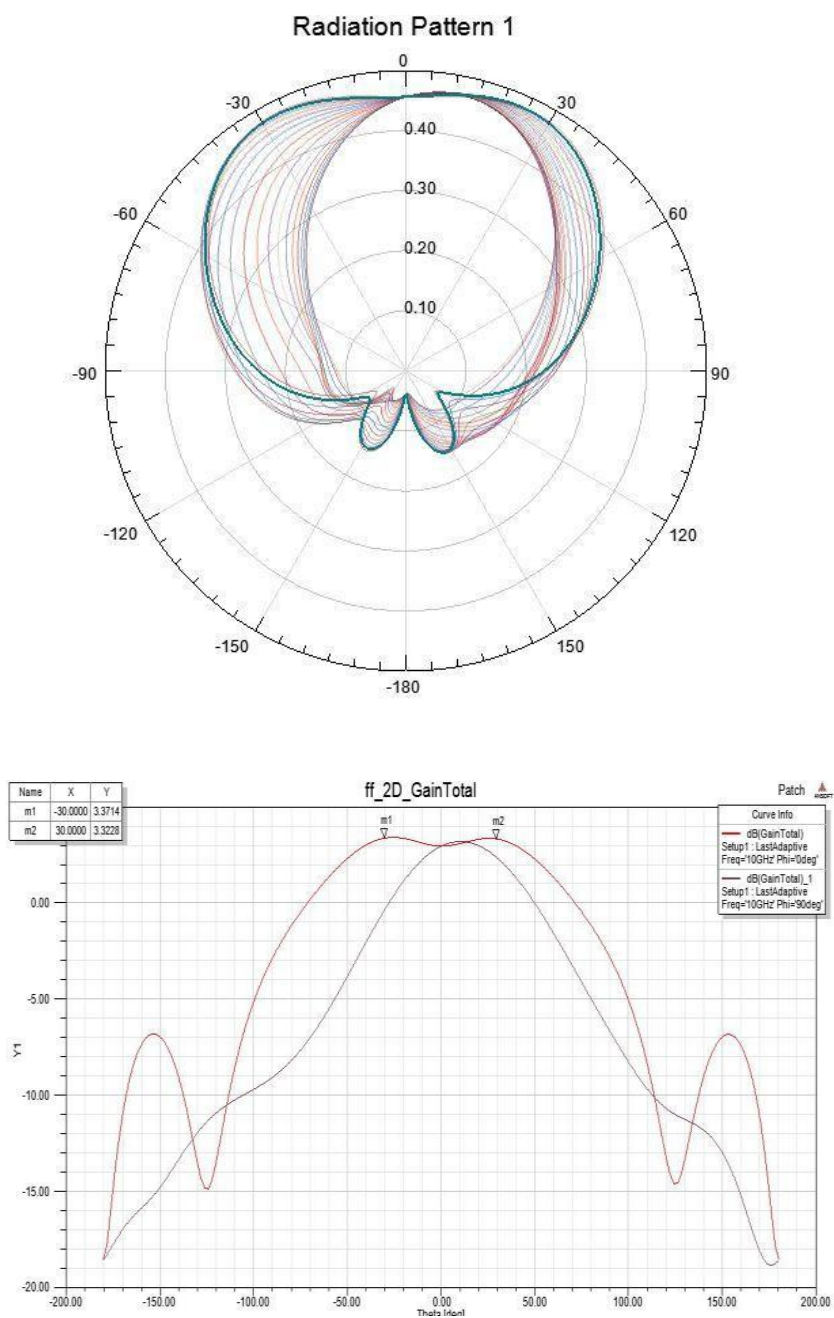

IV. Conclusion:

In this paper, an E-shaped wideband microstrip patch antenna using Air substrate has been designed, simulated, optimized and analyzed using HFSS (High Frequency Structure Simulator) software version 11. The results showing that the antenna can be operated at $7.8 \mathrm{GHz}$ frequency for FR4 substrate. And operated at

10.41GHz.This result is an improvement when compared to the original rectangular microstrip patch antenna and radiation pattern is also being improved.

\section{References:}

[1]. C. A. Balanis, "Antenna Theory, Analysis and Design" John Wiley \& Sons, New York, 1997

[2]. Yang, F.; Xue-Xia Zhang; Xiaoning Ye; Rahmat-Samii, Y.; "Wide- band E-shaped patch antennas for wireless communications," Antennas and Propagation, IEEE Transactions on, vol.49, no.7, pp.1094-1100, Jul 2001

[3]. Hadian, A.M.; Hassani, H.R.; , "Wideband Rectangular Microstrip Patch Antenna with U-Slot," Antennas and Propagation, 2007. EuCAP 2007. The Second European Conference on , vol., no., pp.1- 5, 11-16 Nov. 2007

[4]. B.-K. Ang and B.-K. Chung, "A wideband e-shaped microstrip patch antenna for 5 - $6 \mathrm{GHz}$ wireless communications," Progress In Electromagnetics Research, Vol. 75, 397-407, 2007

[5]. Kumar, G., and K. P. Ray. Broadband Microstrip Antennas. Boston: Artech House, 2003. 